\title{
A conceptual framework for understanding behaviours and attitudes around 'Blue-Green' approaches to Flood-Risk Management
}

\author{
G. Everett \& J. Lamond \\ University of the West of England, UK
}

\begin{abstract}
This study develops a conceptual framework to inform thinking around the social research approach adopted to consider the development of 'Blue-Green' approaches to Flood Risk Management (BG-FRM) in UK cities. The framework informs the manner in which research is conducted and data analysed, to understand current and possible future household and business behaviours as BGFRM becomes more established, and so possibly (or not) more 'normalised', as well as the influences upon these behaviours that can potentially be played by key stakeholders. A conceptual map is drawn up that outlines the key players, their domains of agency and lines of influence concerning larger-scale (neighbourhood, city-level) and smaller-scale (household, business) approaches. A conceptual framework is then developed, thinking about the motivations and barriers that could encourage or inhibit adoption of blue-green approaches and the behaviour changes necessary for their sustainability, before surveying research already conducted in this area. Social Practice Theory (SPT) is suggested as a new manner of framing research to understand the ways in which behaviour may change, or fail to change, and the opportunities and barriers to any such changes. SPT, it is argued, could provide a means by which to consider present behaviours and attitudes, so that we might more effectively look for opportunities to encourage progressive behavioural developments that could increase the chances of BGFRM's sustainability.

Keywords: Blue-Green, Flood-Risk Management, sustainable, behaviour, Social Practice Theory (SPT).
\end{abstract}




\section{Introduction}

With the increased incidence of flood events in recent years and the hypothesis that flooding may increase (or currently be increasing) as a result of development pressures and climate change (King [1], Whitmarsh [2]), governments are taking very seriously the need to deal with the economic and social threats from this (DEFRA [3, 4], Environment Agency [5, 6], SEPA [7]). Thinking is shifting away from simple notions of resisting outright inundation towards developing resilience to flooding - living with water and making space for water gaining prominence in academic literature and policy ([3], Pitt [8], Bowker [9], McBain et al. [10]). Thinking has also moved away from erecting structural defences to establishing softer and more sustainable FRM that retains, filters and makes use of water-flows. The latter has begun happening for a number of reasons: the environmental, aesthetic and socio-economic impacts of structural work; the need to adapt urban areas to cope with a changing climate (using fewer resources and emitting less waste), and an argued need to rethink our relationship with water, reintegrating the natural water-cycle with the urban environment, producing 'water sensitive cities' (Brown et al. [11]. Howe and Mitchell [12], Kazmierczak and Carter [13], BGD [14]). BG-FRM approaches involve improving green infrastructure, raising water-absorption capacity and promoting natural channelling rather than containing and culverting (Abott et al. [15]).

A number of authors have begun publishing research around public attitudes around Blue-Green approaches to Flood Risk Management (BG-FRM) (Bastien et al. [16], Wright et al. [17], Kenyon [18], Apostolaki and Jefferies [19], Werritty [20], Johnson and Priest [21]), some drawing conclusions as to how people will behave around them. Results are apparently quite split between those who found strong preferences for structural defences [20,21] and others who found preference for more sustainable solutions [16, 17]. In Apostolaki's study, awareness of SuDS' flood functions was argued to be low, whilst others have found it to be quite high (around 75\% of respondents [19]).

What has not yet been done is to think about how behaviour might change over time. Public attitudes may be cynicism and mistrust if people are not involved in discussions from the outset. All parties will have a lot to contribute, from scientific-technical assertions about BG-FRM in/efficacy to local knowledge which could dismiss certain options or illustrate that others were relevant and likely to work. Dialogic learning will be imperative to thinking about viable BG-FRM options; for instance, significant differences have been found to exist between actual and perceived SuDS' safety levels (cf. McKissock et al. [22]). Bastien et al. [16] and Apostolaki and Jefferies [19] found small amounts of litter considered significant 'pollution', highlighting the need for agreed maintenance systems. There could initially be hesitancy in uptake, with safety fears around poorly lit green spaces (Bixler and Floyd [23]), water-butts being seen as something for keen 'productive' gardeners (Chappells et al. [24]), and green roofs and permeable paving possibly acceptable or workable only if no behaviour-change were required (cf. Whitmarsh [25] on the asymmetry of intentions and actions concerning climate change). There may be reluctance to 
accept installation and maintenance costs, although Bastien found that 'willingness to pay' for pond amenities could potentially cover installation and maintenance. Behavioural changes required would include emptying water-butts, treating permeable with care and not littering ponds.

Research published so far highlights the need for further research to investigate stakeholder preferences and the potential for change more closely. Key questions would revolve around the normalisation of BG-FRM, how long this takes and how it can be encouraged, as habits change and objects come to be viewed, experienced and used differently. To adapt from Shove and Southerton [26], 'the business of becoming normal involves a two-way process in which [SuDS] respond to their surroundings and at the same time impose something of their own script'. Improving and maintaining BG-FRM would require changes in behaviour to ensure functionality (for example, emptying water-butts, not littering ponds and cleaning permeable paving), and no literature has yet addressed this issue. Structural solutions work to a 'fit and forget' model for most stakeholders. BG-FRM requires that people 'live with water'. The more people interact with BG-FRM, the more they may appreciate, value and want to take care of it. This could be due to changes in how outdoor space is used (improved green areas, relaxation and recreation) or shifts in observation and appreciation of nature as green-cover brought flora and fauna to the city. Another important factor would be the time it took for BG-FRM to offer services referred to (flood protection, habitat provision, leisure space); several years' would be needed for flora-cover to offer significant water-absorbency. So BG-FRM would not be a quick fix, but then larger-scale structural work could take as long from inception to completion. Questions would arise as to how new infrastructure fits into the routines and domestic lives of people affected, how practices could change so they fitted more, and how new practices might come to seem normal. Notions like the necessity of driveways for household parking, preferred aesthetics for rooftops and ease of rooftop drainage as against water-butts would all need to shift over time for true acceptance of a blue-green approach.

This paper will develop a conceptual framework for understanding behaviours around BG-FRM and how these may or may not change over time, looking to the incentives for and barriers to any such changes. It will argue the need to look to future behaviour over current as this will change as new infrastructures become more established and normalised. We argue that new approaches to researching and understanding behaviour are needed, and suggest an effective way forward. Section Two looks at the 'system' and 'stakeholders', mapping out lines of influence for investigation. Section Three outlines the theoretical approach in a Conceptual Framework considering motivations and barriers to adopting BG-FRM. Section Four considers the 'units' of analysis at play and argues for employing a Social Practice Theory (SPT) approach that can account for the disconnect between potential and actual outcomes from environmental programmes, and Section Five concludes. Reasons why further research is needed are outlined over the course of the paper; over the past decade debate has emerged around public opinions of BG-FRM, but this dialogue has 
not yet considered how behaviour might alter with its establishment and normalisation.

\section{Stakeholder map}

Understanding preferences and what affects these (and so behaviour) is a necessary first step in negotiating, and overcoming, barriers and concerns. In order to gain this understanding we need to draw up a stakeholder map before outlining a conceptual framework of perceptions around BG-FRM, and thinking through the motivators and barriers to behavioural changes that could facilitate SuDS' functioning. This work could then be used to monitor shifts in behaviour and perceptions as BG-FRM grew, developed and became more normalised.

The system would need to be bounded to allow for proper analysis and appraisal. An appropriate framing would be city boundaries, although some agents will have wider operations and the watershed may stretch beyond, so factors from outside would need consideration. Nonetheless, framing the 'system' at city level makes sense administratively and will be appropriate for the majority of stakeholders. These would include communities (households, governmental and non-governmental organisations, public service providers and businesses and their representatives), the front end of dealing with inundation. Environmental and wildlife groups will have a strong interest in BG-FRM, as will landowning and advisory bodies such as farms and Natural England [27]. Water companies would be affected by BG-FRM insofar as water supply and disposal of wastewaters would be altered by interventions. The Planning, Development and Building industries would be affected, with new opportunities, responsibilities and demands placed upon their work (RTPI [28], Scottish Government [29]).

Key actors with responsibility for larger-scale BG-FRM would be Local Authority, Environment Agency and national government bodies such as DEFRA (see Figure 1). However the aggregate of household- and business-level BG-FRM

could also make a significant contribution to reducing flooding. The Commission for Architecture and the Built Environment (CABE [30]) found that whilst increasing green space and tree cover in urban areas by $10 \%$ would reduce surface water run-off by around $5 \%$, adding green roofs to all buildings could reduce it by $20 \%$. So this, combined with water-butts and replacement of hardstanding, could impact significantly on potential flooding.

\section{Motivations and barriers}

A first major block to BG-FRM comes when we look at current practice. Despite around 5.5 million properties being at risk from flooding in England and Wales $([5,6]$, DEFRA/EA [31], Wedawatta and Ingirige [32]), action to install measures remains low; around $25 \%$ for households that have previously experienced flooding and only $6 \%$ for those that have not (Thurston et al. [33], Harries [34, 35]). A number of barriers face households, succinctly schematized 


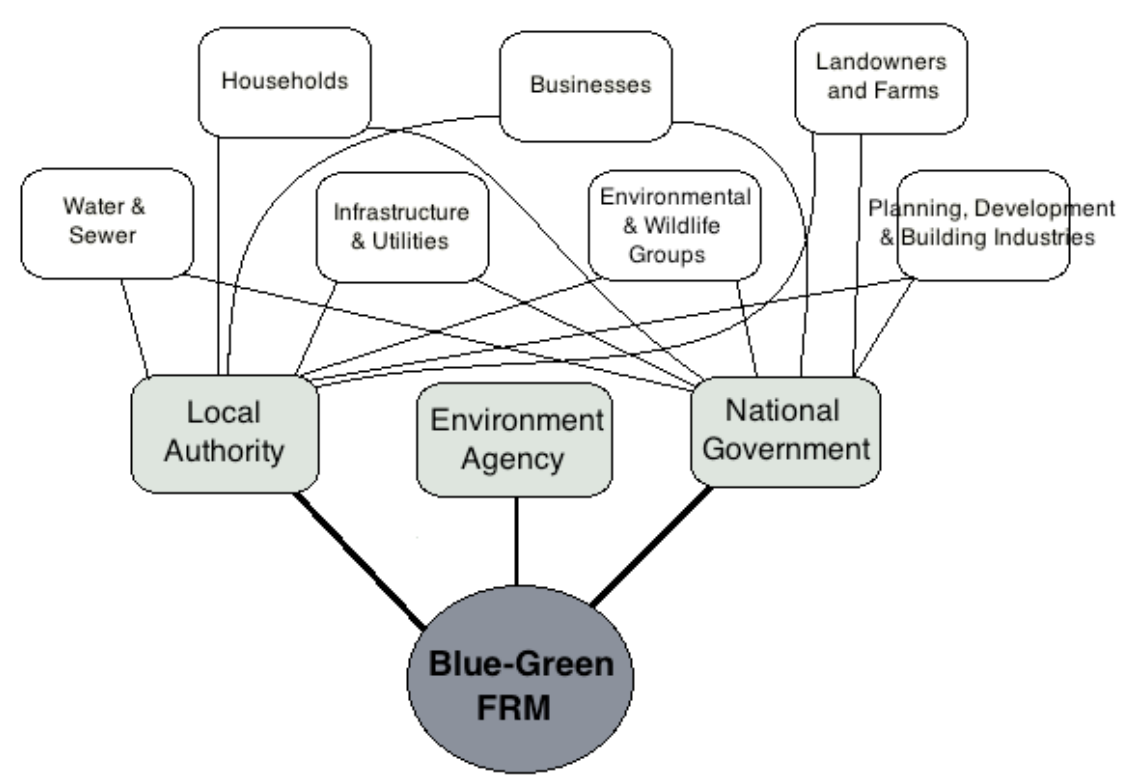

Figure 1: A stakeholder map for BG-FRM in a major UK city.

by Proverbs and Lamond [36] as Desire (awareness, perception, ownership) and Ability (knowledge, finance, belief). They draw up a five-point classification of financial and emotional constraints, informational barriers, aesthetic considerations and timing issues. Each of these points would hold for BG-FRM; finance could be overcome with subsidies, and belief, informational barriers and emotional constraints could be addressed in part through a dialogic approach to developing solutions.

The 'stabilising' factors for BG-FRM would include: hopes of reducing flood-risk; improvements in access to 'natural' spaces; improved recreational and leisure-use areas; improved biodiversity, air quality and reduced heat-island effects; reduced housing and living costs (lower water-use and water-disposal, improved insulation and opportunities for growing food), and improved houseprices. Some of these points could be limited if hard-cover outside houses is considered essential for parking and green-roofs are inaccessible. The 'destabilising' barriers discouraging take-up of BG-FRM could include: awareness that such were an option; understanding what was possible and appropriate for buildings; concern about installation and maintenance costs; belief that they could work; fear of neighbourhood disapproval (for admitting flood risk); safety concerns (individual, with children and ponds, and community, with concerns of antisocial behaviour around green spaces, Bixler and Floyd [23]); concerns about maintenance, impact on house-prices and degentrification (as those who were able moved away), and contrastingly, that improved aesthetics, recreational amenities and flood risk encourage 
gentrification. For businesses, BG-FRM should open up opportunities; as adoption grew, potential returns to capital investment would become more apparent attracting new entrepreneurs, increasing local economic gain and employment, embedding BG-FRM into the local economy and social fabric. These initial lists of suggestions will need investigation with stakeholders, as there will undoubtedly be motivations and barriers not considered here and the degree to which each acts on considerations may differ hugely; to explore these fully would require on-the-ground research in a case study city.

Changing behavioural patterns will be essential to ensuring longer-term BGFRM sustainability; we need to consider influences that make people more or less likely to act. Motivations can be broadly divided into external and internal: external (extrinsic) motivations will come from outside the agent, as fines or subsidies, threats of litigation, or rewards, whilst internal (intrinsic) motivations would depend on self-identity, needs, desires, aspirations and beliefs, the selfsatisfaction or self-worth derived from performing (or not) tasks (Organ [37]). Organ provides a comprehensive literature review of motivation theories and tailors these for looking at household energy efficiency refurbishments. From this, they derive three motivation 'themes', economic, social and environmental, that could broadly be translated to research into BG-FRM and behaviour change. Economic motivations would include savings on water and heating bills from green roofs, installation and maintenance costs as against incentives from local and national government, household income and so spare capital (or lack of) for undertaking works, and questions of how works might affect property value. Social motivations include notions of comfort, people's sense of the role of their 'home' ('a platform for activities, social interactions, a haven, etc.' [37]), social norms, what is seen as 'acceptable behavior' and fashions and tastes of people's social groups, and people's 'locus of control', the extent to which they feel able to affect change through their own actions [37]. Environmental motivations will encompass people's sense of the positive effects stemming from a blue-green approach and will be tied up with their sense of self ('social' motivation). If people's ideal self-image is environmentally conscious and responsible, they may be more likely to adopt blue-green initiatives for the positive environmental payback offered. Because of the nature of water-flows, installation of BG-FRM in parts of a city not directly at flood risk may reduce risk faced in areas that are. Occupiers of buildings in these areas may seemingly have no intrinsic motivation to install devices, the act of so doing being thought of as solely due to external motivations, altruism or improving self-image. However if such infrastructure helps to avoid associated costs and inconveniences of flooding (roads and daily life disrupted, Council Tax increases to cover damages, business costs with disruptions to supply and sales-chains), then 'externals' could be internalised.

A significant demotivating factor could be the 'why me?' or 'what difference can I make?' argument. Blue-Green approaches to flood action, like climate change, will require large-scale collective action to be effective, and so if individuals are asked to freely choose to engage of their own accord then we may end up with a 'tragedy of the commons' (Hardin [38], cf. Lorenzoni et al. [39]) where there is no incentive to undertake the changes required if people suspect 
their neighbours will free-ride on the benefits. Activities will need to be scaled up to community level, which in turn necessitates dialogue working towards consensus on action. Local authority or government regulation may be needed to ensure all parties act appropriately, but given that all would stand to benefit from BG-FRM over time then this may be avoidable through dialogue and coconstruction of viable preferred solutions.

\section{Social Practice Theory (SPT)}

To think through how different actors and groups may respond to BG-FRM, how they might behave and how behaviour could change over time, we will need to have an idea of: the 'units' under consideration; the de/stabilising influences affecting behaviour, and a model for how these influences affect behaviour. Traditionally, much social theory has been very broadly divisible into two camps or approaches: Atomism (individualistic utilitarianism), wherein rational individuals are the units of agency, acting to advance their own interests having assessed costs and benefits (homo economicus); and Structuralism, wherein 'human behaviour is an 'effect' of symbolic structures in the 'unconscious' mind' (Reckwitz [40]), social norms, values and 'rules' that determine how people behave. Under the former, relevant units of agency would be people within households, businesses, Councils, Government, Environment Agency and so forth; changing the behaviour of populations would mean simply shifting perceptions of costs and benefits - providing free home flood surveys and subsidising the cost of defence measures, for example, as advocated in DEFRA documents [4]. However as DEFRA's Resilience Grants Pilot Projects [41] found, even with free provision of flood assessments, protection devices and installation, only $83 \%$ of households took up the initiative, indicating other factors were also at play. The structuralist tradition has also been criticised for being over-determined and not allowing space for changes in practice, both gradual and revolutionary.

Social theory has thus for some time been seeking to move beyond this restrictive dualism of rationalistic atomism and deterministic structuralism. One response has been a 'family' of 'theories of social practice', influenced by Pierre Bourdieu, Anthony Giddens, later Michel Foucault, Judith Butler, Bruno Latour and others. These Social Practice Theory (SPT) approaches adopt a both/and positioning to overcome the agency/structure dualism; situating their analysis on the (series of) practices of (groups of) individuals [40]. These sets of practices are understood as forming 'shared behavioural routines' that are argued to be coconstitutive of individuals. Individual actors retain their agency in a contextualised fashion, continually re-producing practices and so contributing to shifts and alterations at each turn, but the set of social practices is the unit of analysis rather than the individual actor (Spaargaren [42]).

Social practices have been variously defined by those seeking to focus the discussion. A widely cited quote we might reasonably use is provided by Reckwitz [40]: 
A practice is a routinized type of behaviour which consists of several elements, interconnected to one another: forms of bodily activities, forms of mental activities, 'things' and their use, a background knowledge in the form of understanding, know-how, states of emotion and motivational knowledge. A practice - a way of cooking, of consuming, of working, of investigating, of taking care of oneself or of others, etc. - forms so to speak a 'block' whose existence necessarily depends on the existence and specific interconnectedness of these elements, and which cannot be reduced to any one of these single elements.

So practice refers to an ensemble of factors 'constitutive of particular domains of social life' (farming, business, voting, teaching, recreation, industry, religion), a 'set of considerations' that shape how people act (Schatzki [43]). As Schatzki elaborates, a practice 'rules action not by specifying particular actions to perform, but by offering matters to be taken account of ... it qualifies the how as opposed to the what of actions'. These notions of practice do not support structuralist determinism, rather they serve quite the contrary. Practices and so behaviour can change through the development of practices themselves: '[ $t$ ]he concept of practice inherently combines a capacity to account for both reproduction and innovation ... practices also contain the seeds of constant change' (Warde [44]). As practices are re-performed by different agents, certain parties may hold to older variants, some perform currently dominant types and others seek to replace conventions with new approaches. In this way, economic, political and technological developments, cultural and historical influences and other practices can all affect the development of a practice (Shove et al. [45]).

These new approaches are finding use within environmental-social sciences, exploring spaces for changes in practice to enable the greening of consumption and resource-use (Shove and Pantzar [46], Shove [47], Spaargaren and Mol [48]). Environmental groups long been preoccupied with awareness-raising around carbon footprint, but research indicates awareness is 'a weak predictor' of actual behaviour, meaning we could usefully look to social practices for possibilities of change (Spaargaren [42]). Parallels can be drawn with broader social practice changes that communities will need to display for BG-FRM to be sustainable over the longer-term. In Shove's analyses of the freezer's place in modern society, for example, she 'concentrates on the construction and transformation of collective convention' (Shove and Southerton [26], Shove [47]); changing narratives around the freezer's purpose and function, the development of the frozen food industry and microwave, perceived increasing demands upon time and the positioning of the freezer as a solution to this. In this way, we look beyond individual preferences and habits without entirely discounting them, to ways in which reasonable, 'practical' and desirable options are framed over time. Shove and Southerton [26] quote Hackett and Lutzenhiser [49]: '[w] hat [objects] are good for is a consequence, not a determinant, of their use ... they have consummatory as well as instrumental meaning'. We can say the same of many BG-FRM options.

Use of SPT will be shaped by the nature of the investigation. Research would look to future behaviour from stated current behaviour, preferences and 
intentions, rather than being a reinterpretation of historical data as with Shove. Examples of behaviour change over time could be explored from BG-FRM installed some years previously, although of course the socio-economic and cultural context in each case would differ from contemporary proposals. SPT would be deployed as a heuristic device, 'a sensitizing 'framework' for empirical research' rather than an overbearing theoretical structure determining what should be seen and how it should be interpreted (Reckwitz [40]). Using SPT to inform a conceptual framework would allow researchers to explore how different practices could make the sustainability of BG-FRM more or less difficult and to consider the conditions allowing for shifts in practices to increase sustainable behaviour (and where responsibility for those conditions lie). The research would look beyond individual respondents' stated behaviour to consider 'the many institutions involved in structuring possible courses of action' in the hope of 'making some very much more likely than others' (Shove [47]).

\section{Conclusion}

This paper has outlined a conceptual framework to guide how social research into practices (and changes in practices) regarding city-level adaptations to increase BG-FRM could be undertaken. Principal stakeholders have been provisionally identified and lines of influence between these for BG-FRM approaches suggested. Introducing BG-FRM to a city will be a complex matter affecting many different stakeholders, and this is but one reason why the process will need to be as inclusive as possible from the very beginning, to ensure that all relevant and concerned voices are being listened to.

The stabilising and destabilising factors and motivations affecting people's behaviour have also been outlined and considered. While some research has looked at a time-slice of attitudes, none has as yet tried to think around why and how behaviour patterns might change as infrastructure developed and became more normalised. This is an essential next step in thinking about the viability of BG-FRM over time, understanding more about people's current thinking and how this could develop, to develop a clearer picture of likely outcomes. The Social Practice lens has identified new avenues for interrogating this behaviour. Studying this further using an SPT approach will require close work with communities and other stakeholders at the start and throughout the proposed changes, to understand how multiple considerations might settle or shift regarding FRM options under a variety of hypothetical situations over time.

\section{Acknowledgements}

This research was performed as part of an interdisciplinary project programme undertaken by the Blue-Green Cities Research Consortium (www.bluegreencities.ac.uk). The Consortium is funded by the UK Engineering and Physical Sciences Research Council under grant EP/K013661/1, with additional contributions from the Environment Agency, Rivers Agency (Northern Ireland) and the National Science Foundation. 


\section{References}

[1] King, D.A., Climate change science: adapt, mitigate, or ignore? Science, 303(5655), pp. 176-177, 2004.

[2] Whitmarsh, L., Are flood victims more concerned about climate change than other people? The role of direct experience in risk perception and behavioural response. Journal of Risk Research, 11(3), pp. 351-374, 2008.

[3] DEFRA, Making Space for Water. Defra: London, 2005.

[4] DEFRA, Consultation on policy options for promoting property-level flood protection and resilience, Defra: London, 2008a.

[5] Environment Agency, Flooding in England: A National Assessment of Flood Risk, Environment Agency: Bristol, 2009.

[6] Environment Agency, Flooding in Wales: A National Assessment of Flood Risk, Environment Agency: Bristol, 2009.

[7] Scottish Environment Protection Agency, Flooding in Scotland: A Consultation on Potentially Vulnerable Areas and Local Plan Districts. SEPA: Stirling, 2009.

[8] Pitt, M., Learning Lessons from the 2007 Floods: An Independent Review, Cabinet Office: London, 2008.

[9] Bowker, P., Flood Resistance and Resilience Solutions: An R\&D Scoping Study, Defra: London, 2007.

[10] McBain, W., Wilkes, D. \& Retter, M., Flood Resilience and Resistance for Critical Infrastructure, CIRIA: London, 2010.

[11] Brown, R., Keath, N. \& Wong, T., Transitioning to water sensitive cities: historical, current and future transition states. 11th International Conference on Urban Drainage, 10, 2008.

[12] Howe, C. \& Mitchell, C., Water Sensitive Cities, IWA Publishing: London, 2012.

[13] Kazmierczak, A. \& Carter, J., Adaptation to climate change using green and blue infrastructure. A database of case studies. University of Manchester: Manchester, 2010.

[14] Blue-Green Dream website, http://bgd.org.uk, accessed on $10^{\text {th }}$ September 2013, Imperial College London: London, 2013.

[15] Abbot, J., Davies, P., Simkins, P., Morgan, C., Levin, D. \& Robinson, P., Creating Water Sensitive Places - scoping the potential for Water Sensitive Urban Design in the UK, 2013.

[16] Bastien, N., Arthur, S. \& McLoughlin, M.J., Valuing amenity: public perceptions of sustainable drainage systems ponds. Water and Environment Journal, 26(1), pp. 19-29, 2011.

[17] Wright, G.B. Arthur, S., Bowles, G., Bastien, N. \& Unwin, D., Urban creep in Scotland: stakeholder perceptions, quantification and cost implications of permeable solutions. Water \& Environment Journal, 25(4), pp. 513-521, 2011.

[18] Kenyon, W., Evaluating flood risk management options in Scotland: A participant-led multi-criteria approach. Ecological Economics, 64(1), pp. 70-81, 2007. 
[19] Apostolaki, S. \& Jefferies, C., Social impacts of stormwater management techniques including river management and SUDS. Final report, SUDS01. Environment Agency: Bristol, 2005.

[20] Werritty, A., Sustainable flood management: oxymoron or new paradigm? Area, 38(1), pp. 16-23, 2006.

[21] Johnson, C.L. \& Priest, S.J., Flood Risk Management in England: A Changing Landscape of Risk Responsibility? International Journal of Water Resources Development, 24(4), pp. 513-525, 2008.

[22] McKissock, G., D’Arcy, B.J., Wild, T.C., Usman, F. \& Wright, P.W., An Evaluation of SuDS Guidance in Scotland, Diffuse Pollution Conference, Dublin, 2003.

[23] Bixler, R.D. \& Floyd, M.F., Nature is Scary, Disgusting, Uncomfortable. Environment \& Behaviour, 29(4), pp. 443-467, 1997.

[24] Chappells, H., Medd, W. \& Shove, E., Disruption and change: drought and the inconspicuous dynamics of garden lives. Social \& Cultural Geography, 12(7), pp. 701-715, 2011.

[25] Whitmarsh, L. Behavioural Responses to Climate Change: Asymmetry of intentions and impacts. Journal of Environmental Psychology, 29, pp. 1323, 2009.

[26] Shove, E. \& Southerton, D., Defrosting the Freezer: From Novelty to Convenience. Journal of Material Culture, 5(3), pp. 301-319, 2000.

[27] Natural England, Green Infrastructure Guidance, Natural England: Sheffield, 2009.

[28] RTPI, Briefing on Green Infrastructure in the United Kingdom, RTPI: London, 2013.

[29] Scottish Government, Green Infrastructure: Design and placemaking, The Scottish Government: Edinburgh, 2011.

[30] CABE, Using Green Infrastructure to Alleviate Flood Risk, Commission for Architecture \& the Built Environment: London, 2011.

[31] DEFRA/Environment Agency, The Appraisal of Human-related Intangible Impacts of Flooding, DEFRA: London, 2004.

[32] Wedawatta, G. \& Ingirige, B., Resilience and adaptation of small and medium-sized enterprises to flood risk. Disaster Prevention and Management, 21(4), pp. 474-488, 2012.

[33] Thurston, N., Finlinson, B. \& Breakspear, R., Developing the Evidence Base for Flood Resistance and Resilience: Summary Report, Environment Agency: Bristol, 2008.

[34] Harries, T., Household Flood Protection Grants: The householder perspective. Defra and Environment Agency Flood and Coastal Risk Management Conference, 2010.

[35] Harries, T., The anticipated emotional consequences of adaptive behavior - impacts on the take-up of household flood-protection measures. Environmental Planning A, 44(3), pp. 649-668, 2012.

[36] Proverbs, D. \& Lamond, J., The Barriers to Resilient Reinstatement of Flood Damaged Homes. 4th International i-Rec Conference, 2008. 
[37] Organ, S., Motivations for energy efficiency refurbishment in owneroccupied housing. Structural Survey, 31(2), pp. 101-120, 2013.

[38] Hardin, G.J., 1968. The Tragedy of the Commons. Science, 1968.

[39] Lorenzoni, I., Nicholson-Cole, S. \& Whitmarsh, L., Barriers perceived to engaging with climate change among the UK public and their policy implications. Global Environmental Change, 17(3-4), pp. 445-459, 2007.

[40] Reckwitz, A., Toward a Theory of Social Practices: A Development in Culturalist Theorizing. European Journal of Social Theory, 5(2), pp. 243263, 2002.

[41] DEFRA, Resilience Grants Pilot Projects. DEFRA: London, 2008.

[42] Spaargaren, G., Theories of practices. Global Environmental Change, 21, pp. 813-822.

[43] Schatzki, T.R., Social Practices: A Wittgenstinian Approach to Human Activity and the Social. Cambridge University Press: Cambridge, 1996.

[44] Warde, A., Consumption and Theories of Practice. Journal of Consumer Culture, 5(2), pp. 131-153, 2005.

[45] Shove, E., Pantzar, M. \& Watson, M., The Dynamics of Social Practice. SAGE: London, 2012.

[46] Shove, E. \& Pantzar, M., Consumers, Producers and Practices: Understanding the invention and reinvention of Nordic walking. Journal of Consumer Culture, 5(1), pp. 43-64, 2005.

[47] Shove, E., Social Theory and Climate Change. Theory Culture and Society, 27(2-3), pp. 277-288, 2010.

[48] Spaargaren, G. \& Mol, A. Greening Global Consumption. Global Environmental Change, 18(3), pp. 350-359, 2008.

[49] Hackett, B. \& Lutzenhiser, L., The Unity of Self and Object. Western Folklore, 44(4), pp. 317-324, 1985. 